A bacteriological report by Captain J. A. Arkwright, R.A.M.C., was as follows :-“(a) B. typhos. para A in pus removed from empyema. (b) Ten days after operation: Positive agglutination of B. typh. A 1/400; negative B. typh. B 1/100.'

The chief interest lies in the bacteriological report as to the presence of $B$. typhosus para. $A$ in the pus. The question as to whether the patient had a primary lung affection remains uncertain. At first $I$ thought the collapse after the operation (about 12 hours) was due to a pneumonic crisis, but the clinical signs gave no support to that, and with the evacuation of the pus all pulmonary signs cleared up rapidly. The early removal of the tube is interesting, and was possible because we were dealing with a very acute empyema.

\section{THE SURGICAL TREATMENT OF THE ERYTHEMA INDURATUM OF BAZIN.}

By Emmanuel Kondeleon, M.D., IATE SURGEON TO THE CIVIL HOSPITAL, ATHENS.

IN a case of erythema induratum I have tried the excision of the indurated parts with a good result. The following are my notes :-

The patient was a lymphatic boy, aged 15 years, whose mother died from tuberculosis. He himself had never any tuberculous localisation before. Five months ago, two symmetrical and large indurated masses appeared at the same time under the skin of the outer surface of both arms. In some parts the skin was violet-coloured but in others it appeared nearly normal. These hard masses of the subcutaneous tissue extended over the outer and posterior surface of the arms and reached the elbow. Only their inner surface was free. The underlying muscles were not adherent to the indurated parts, which could easily be raised by the hand. Five days later two subcutaneous, hard, but not quite symmetrical, nodules appeared, one on the midale of the anterior surface of the right thigh, and the other on the middle of the posterior surface of the left thigh. They were not surrounded by the induration, which was so characteristic in the arms, and showed no difference in their appearance in the course of five months.

The histological examination of indurated parts taken from the left arm, made by Professor Katsaras, showed tubercles in the hard subcutaneous tissue, formed mostly by epithelioid cells. In some of them a peripheral zone of lymphatic cells was observed. A certain number of giant cells were also to be seen, some being of the type Langhans, with their nucleus situated round the cell like a ring, while others had the nucleus in the centre. The tubercles were either isolated or arranged in groups of from three to four tubercles each. The lymphatic vessels were very much enlarged. In some parts the enlargement was so prominent that the cysts therefrom were visible to the naked eye. A close relation existed between the tubercles and the enlarged lymphatic vessels, the former having developed round the lymphatic vessels. A certain number of tubercles were found in a state of beginning organisation, produced by the evolution of the epithelioid cells into a ripe connective tissue. The whole area round the tubercles was very thick.

From the above histological examination it was clear that the case belonged to that singular induration of the subcutaneous tissue first described by the French author Bazin under the name "erythema induratum." Further notes :-

After the excision made for the histological examination $I$ observed that the hard, infiltrated mass of the left arm disappeared round the scar. This encouraged me to remove the diseased parts on a larger scale. Thus on May 16th I excised all the indurated subcutaneous tissue of the left arm, while nothing was done on the right. Under local anæs thesia I made an incision 6 inches long on the outer surface of the left arm, and removed all hard fat and connective tissue going from the skin to the healthy muscular layer. Only a small part of the induration could not be removed through this incision. A few weeks later the whole indurated area except the small unremoved part was soft. The skin was still thicker than usual, but normal in colour. The difference between the right arm not operated upon and the left was remarkable. Nearly three months have elapsed since the operation, and the induration has not recurred.

The erythema induration is a mild form of tuberculous infection whose localisation heals usually by itself. The majority of these cases do not require any surgical measure, but I think that the excision of the diseased parts may be reserved for those cases in which the induration extending over a large part of the arms or lower extremities lasts for a long time and impedes their function.

\section{A CASE OF HEREDITARY SYNDACTYLY.}

\author{
By W. E. Le Gros Clark.
}

(From the Out-patient Department of St. Thomas's Hospital.)

THE appended skiagram shows an interesting anomaly, which is worthy of being recorded if, as I believe, no similar case has hitherto been observed.

The hand is that of a girl aged 20 who attended the casualty department of St. Thomas's Hospital some time ago. Both hands were affected in the same way, and on superficial examination the three radial digits appeared to be totally absent, while the two ulnar digits presented the normal segmentation and were syndactylous. The patient informed me that her father and two brothers were affected by the same deformity. The skiagram presents some difficulty of

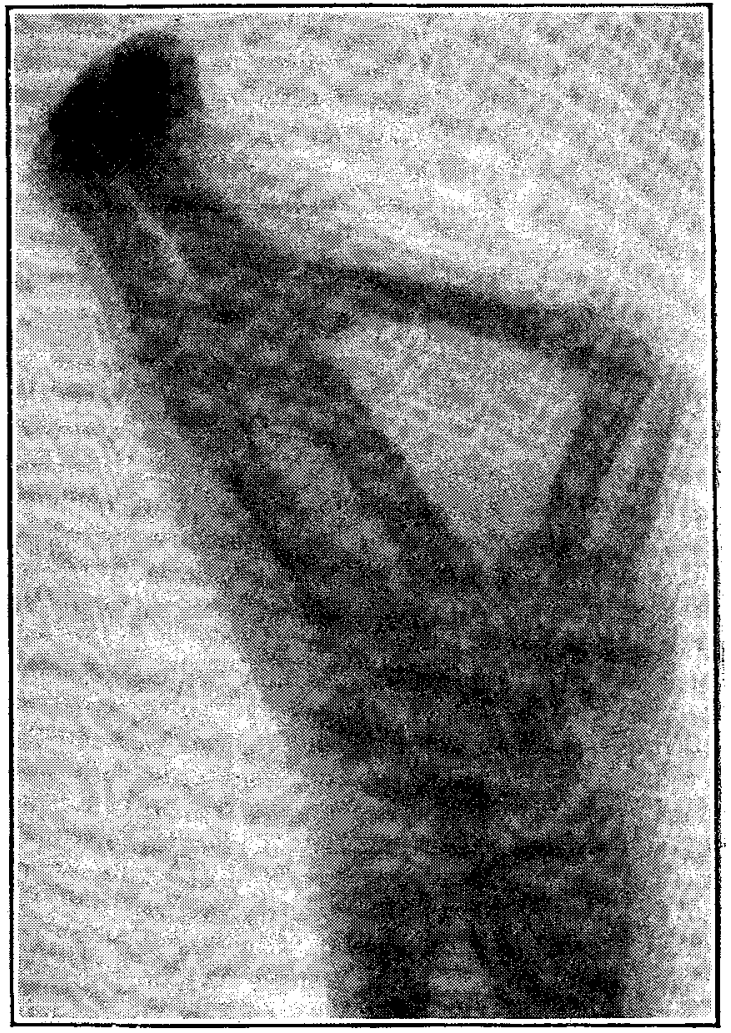

interpretation. The three mesial metacarpals, as shown by their shape and carpal articulation, appear to be normally developed. Lying horizontally between the heads of the third and fourth metacarpals is another metacarpal bone, which is either the first or second metacarpal bone displaced from its normal position, or, as seems more probable, a reduplication of the third metacarpal. It articulates proximally with the head of the latter bone, and distally with the lateral of the two proximal phalanges. This phalanx, however, from its unusual width, appears to be the result of the fusion of at least two phalangeal elements, probably the third and fourth. The identification of the lateral metacarpal in the skiagram is obscure, for it may represent either the first or second metacarpal element.

I wish to express my gratitude to Mr. Cyril Nitch, surgeonin-charge, for his kindness in allowing me to make a note of this case.

The Care of Teeth IN Schools.-The School Dentists' Society is circulating the synopsis of a work recently published on school dentistry which it considers may suggest topics for discussion by members of the society and others interested in school dentistry. Among the general contents are chapters on school dentistry and infectious and nervous diseases, and on the anomalies and deformities of the teeth and jaws in children, caused by general debility. Special articles are included on the position of school dentists, and on the inspection and examination methods of teeth in the schools, while examples are given from German sources of the general management of dental clinics in Berlin. 